\title{
FonOS QUE REALIZAN LA SECUENCIA GRAFÉMICA "HU+VOCAL" EN 17 SUJETOS DE CONCEPCiÓN E HIPÓTESIS INICIAL SOBRE SU ORGANIZACIÓN FONOLÓGICA*
}

\author{
Elizabeth H. Aguilar Fernández ** \\ Gastón F. Salamanca Gutiérrez ${ }^{* * *}$
}

\section{Resumen}

En este artículo presentamos los resultados obtenidos al elicitar enunciados que contienen la secuencia "hu+vocal". Concretamente, presentamos: a) los fonos que instancian dicha secuencia y b) una propuesta inicial de interpretación con respecto a la organización fonológica de dichos segmentos. Para cumplir estos objetivos se utilizan dos instrumentos: el instrumento que se presenta en Cifuentes y Salamanca (2012) -específicamente, dos de las tres tareas que allí se contienen- y la lectura en voz alta. Esto, con la finalidad de abarcar dos estilos de habla: (semi)espontánea y cuidada. Finalmente, tanto los hallazgos obtenidos, como la hipótesis de interpretación fonémica, se comparan con los resultados contenidos en Calvo (2008).

Palabras clave: Fonología, segmentos deslizados, interpretación fonémica.

\section{Phones THAT REALIZE THE GRAPHEMIC SECUENCE "HU+VOWEL" IN 17 INDIVIDUALS FROM CONCEPCIÓN AND INITIAL HIPOTHESIS ON ITS PHONOLOGICAL ORGANIZATION}

\begin{abstract}
This work will be focused on one secuence in particular: the one represented by the graphemes "hu+vowel". In addition, according to the findings, we postulate and discuss an initial hypothesis about the phonological organization of these segments. In order to accomplish those objectives two instruments are used: The instrument proposed by Cifuentes and Salamanca (2012) - specifically, two out of three tasks contained there- and the out loud reading. All this in order to cover two speech styles: (semi)spontaneous speech and careful speech. Finally, both the findings obtained and the phonemic interpretation hypothesis are compared with the results contained in Calvo (2008).
\end{abstract}

Key words: Phonology, glides, phonological organization.

Recibido: 10-05-2013

Aceptado: 15-08-2013

* Este artículo es fruto de la tesis de Magíster en Lingüística Aplicada en Universidad de Concepción.

** Chilena, Magíster en Lingüística, Facultad de Humanidades y Artes, Universidad de Concepción, Concepción, Chile. aguilar.elita@gmail.com

*** Chileno, Doctor en Lingüística, Departamento de Español, Facultad de Humanidades y Artes, Universidad de Concepción, Concepción, Chile. gaston.salamanca@gmail.com 


\section{Introducción}

El tema de los segmentos deslizados del español [j] (e [i]) y [w] (y [u]]) se mantiene siempre vigente y en constante estudio. Es así como en los estudios fonético-fonológicos clásicos del español (Navarro (1918), Alarcos (1961), Harris (1983), Quilis y Fernández (1999)) se plantea ya una discusión y clasificación de dichos segmentos dentro del inventario fonológico de la lengua. Estudios y tesis más recientes vuelven a esta discusión. Una de ellas es la tesis doctoral de Lourdes Aguilar (1994) Los procesos Fonológicos y su manifestación fonética en diferentes situaciones comunicativas: La alternancia Vocal / Semiconsonante / Consonante. En este estudio se abordan las diferentes cuestiones que afectan a la fonética y fonología del español, y, mediante el análisis de datos procedentes del análisis acústico de un experimento controlado de muestras de habla, se presentan propuestas acerca del estatus fonológico de los segmentos críticos.

El estudio más reciente al que hemos podido acceder es el realizado por Calvo (2008) "Las Semiconsonantes y Semivocales en los diptongos del español: propuesta de análisis fonológico". Aquí, la autora presenta una investigación acerca del estatus fonológico, aún en discusión, de los sonidos deslizados en los diptongos del español de Costa Rica, para lo cual realiza un recorrido cronológico por las diferentes propuestas de autores esenciales en el tema, pasando por perspectivas estructuralistas y generativistas. Luego de este recorrido, adopta una hipótesis que será confirmada mediante una investigación centrada en el habla espontánea de Costa Rica.

Sin embargo, uno de los problemas que presentan estos trabajos es que, generalmente, organizan fonológicamente un material fonético cuya naturaleza se postula sin una base empírica o se determina de acuerdo con el idiolecto del investigador. En este contexto, dos objetivos centrales que nos propusimos con nuestra investigación fue, por una parte, instalar el tema de los segmentos deslizados como un tópico relevante para la discusión en fonética/fonología sobre el español de Chile, y, por otra, proveer una cantidad de datos fonéticos confiables, que contribuyan a su adecuada interpretación fonológica en esta variante del español. Ahora, dada la envergadura que supondría la recogida de datos para la interpretación de todo el continuum que va de / i / a / dz/ y de / u / a /g/, en esta investigación nos focalizamos en determinar qué fonos realizan

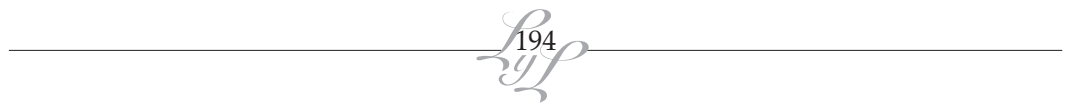


la secuencia "hu+vocal" (como en "huevo", "huincha", etc.), en distintos contextos, en una muestra de 17 sujetos de la comuna de Concepción, Chile, y, de acuerdo con ello, discutir una hipótesis inicial con respecto a la organización fonológica de dichos segmentos.

Para cumplir estos objetivos se utilizan dos instrumentos: el instrumento que se presenta en Cifuentes y Salamanca (2012) -específicamente, dos de las tres tareas que allí se contienen- y la lectura en voz alta. Esto, con la finalidad de abarcar dos estilos de habla: (semi)espontánea y cuidada.

Finalmente, los hallazgos obtenidos se comparan con los resultados contenidos en Calvo (2008).

\section{Marco de referencia y discusión bibliográfica}

Esta investigación se inscribe dentro de la fonética articulatoria descriptiva, tal y como se presenta, entre otros muchos autores, en Martínez Celdrán (1993, 1996), Quilis y Fernández (1973 y 1999), Obediente (2007) y Burquest (2009).

En relación con el tema que nos ocupa, podemos dividir los precedentes bibliográficos en dos categorías: aquellos que pertenecen a la tradición peninsular, y no peninsular. Respecto de la primera, se relevan, entre otros, los aportes de Navarro Tomás (1918); Alarcos (1961); Mosterín (1981); Martínez Celdrán (1993, 1996); Aguilar (1994); Quilis y Fernández (1999); y Martínez Celdrán, Fernández Planas y Carrera (2003). En relación con la tradición no peninsular, se relevan los aportes de los siguientes autores: Bowen y Stockwell (1955), Saporta (1956), Cressey (1978), Harris (1983), D'Introno y otros (1995), y Núñez Cedeño y Morales Font (1999).

En relación con esta segunda tradición (no peninsular), podemos señalar que en Latinoamérica no abundan las contribuciones en este ámbito. El trabajo de Calvo (2008) constituye, en este contexto, una excepción relevante. Sin embargo, podemos encontrar trabajos que en el contexto de descripciones más amplias presentan una propuesta de interpretación de los fonos deslizados. Damos, con algún detalle, una descripción de ellos:

Obediente (2007). Este autor venezolano propone un inventario vocálico del español, en el cual incluye las glides [j] palatal, deslabializada, asilábica y [w] velar, labializada, asilábica; ambas poseen como contexto 
de aparición los diptongos y triptongos de nuestra lengua. Frente a la discusión que nos ocupa, este autor opta por obviar la distinción entre semivocales y semiconsonantes, y prefiere el término más global y derivado de la fonética inglesa 'glides' o 'articulaciones de deslizamiento' o 'deslizadas'. De esa forma, todo alófono no silábico de /i / o / u/, será considerado glide y representado por [j] y [w], respectivamente, sin importar su posición con respecto al núcleo silábico.

Calvo (2008). Como hemos señalado, esta autora costarricense publica en 2008 su trabajo "Las semiconsonantes y las semivocales en los diptongos del español: propuesta de análisis fonológico". En él, junto con resumir las posiciones más prominentes con respecto al estatus de las glides en español, realiza una investigación que le permite afirmar que en el español de Costa Rica sólo las vocales / i / y / u/ pueden ser consideradas fonemas, ya que pueden formar núcleo silábico con la vocal del diptongo. Además, confirma que en los diptongos en posición inicial de sílaba las deslizadas presentan realizaciones consonánticas, debido al refuerzo de ataque en posición inicial de palabra.

Cepeda (1991). En Chile, no existen estudios focalizados en los sonidos glides. Sólo es posible encontrar clasificaciones generales que enfocan el trabajo en determinadas ciudades del país. Uno de estos trabajos es "Las consonantes de Valdivia" (Cepeda, 1991). Aquí, la autora describe desde un punto de vista sincrónico el sistema fonológico del español urbano de Valdivia, individualizando las diferentes variables sociolingüísticas que se distinguen dentro de él. La autora presenta una visión teórica diferente a las propuestas anteriores, en cuanto al estatus fonológico del fono [j], ya que tras su estudio de campo concluye que se trata de un fonema del español de Valdivia y no un alófono de la vocal /i / . Para ello, se basa en su frecuencia y en su mayor gama de contornos de ocurrencia. El comportamiento de distribución complementaria del fonema concuerda con el del grupo / bdg/ de Cressey, ya que los fonos no continuos africados ocurren en posición inicial absoluta y después de consonante nasal (como en "y[ó\#kr]eo" ‘yo creo'), y los continuos en posición intervocálica (como en "est[u\$ðj]ar" 'estudiar'). En el caso del fono [w], lo considera un alófono del fonema / $\mathbf{\gamma}$ /, que es el de más amplia realización y aquel que se refuerza en contornos de fuerza silábica. En consecuencia, el alófono [w] aproximante labio-dorso-velar sonoro, tal

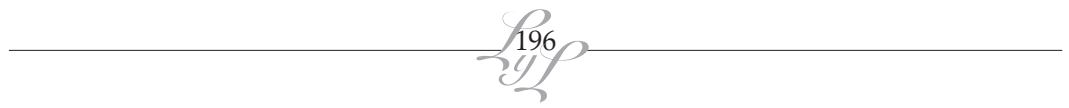


como lo describe la autora, ocurre en posiciones de debilitamiento silábico e intervocálica. Por otra parte, es posible deducir de las transcripciones de las palabras "ca[w]le" y "pr[we]ba", que Cepeda no distingue entre semivocal y semiconsonante, esto es, sólo reconoce un fono debilitado, ya sea en diptongo creciente como en decreciente.

\section{Preguntas de investigación}

2.1. ¿Cuáles son las realizaciones fónicas de la secuencia grafémica "hu+vocal" en 17 sujetos de la comuna de Concepción, Chile?

2.2.¿Qué organización fonológica inicial se aconseja a partir de los segmentos encontrados?

2.3. ¿Hay diferencias prominentes en la producción de esta secuencia en sujetos de sexo masculino y sexo femenino?

\section{Objetivos}

3.1. Determinar qué segmento(s) realiza(n) la secuencia grafémica "hu+vocal" en un grupo de 17 sujetos de la comuna de Concepción.

3.2. Proponer una hipótesis inicial con respecto a la organización fonológica de los segmentos encontrados.

3.3. Destacar aspectos prominentes que emergen al comparar los resultados obtenidos por hombres y mujeres.

\section{Metodología}

\subsection{Sujetos}

Los sujetos que participaron en esta investigación fueron 17: 8 hombres y 9 mujeres, cuyas edades fluctuaban entre los 18 y los 20 años, y pertenecían a las carreras Ingeniería en Biotecnología Vegetal e Ingeniería en Conservación de Recursos Naturales de la Universidad de Concepción. Se prefirió trabajar con sujetos del ámbito de las ingenierías por tener menos contacto formal con los estudios fonético-fonológicos y, en consecuencia, presentar menos probabilidades de que detectaran el fenómeno que se investigaba (y, con ello, una posible distorsión de los datos elicitados). 


\subsection{Instrumentos}

El primer instrumento utilizado es el que se presenta en Cifuentes y Salamanca (2012) ${ }^{1}$, el cual se basa en la asociación de estímulos mixtos (imagen y enunciado). De él, se seleccionaron dos tareas: la primera, consiste en que los hablantes deben recordar, ordenar y elicitar, a través de una imagen, un enunciado que tiene un orden no canónico, asociado previamente con dicha imagen a través de una grabación; la segunda tarea consiste en la pronunciación, a velocidad "normal", de algunos enunciados previamente ralentizados. En ambos casos, los enunciados son grabados, previamente, en español, por un hablante extranjero. Ambas tareas, como ya probara Cifuentes (2011), permiten recoger datos en un estilo de habla (semi)espontáneo.

El segundo instrumento consistió en una lista de 27 enunciados -similares a los elicitados con el instrumento descrito anteriormente-, que los sujetos leían en voz alta. Preferimos no utilizar exactamente los mismos enunciados para no entregar pistas determinantes a los sujetos con respecto al fenómeno estudiado y, con ello, la posibilidad de que su habla fuera más controlada. Eso sí, las palabras con la secuencia "hu+vocal" y los contextos fónicos considerados fueron los mismos.

Los enunciados producidos por los sujetos se registraron en una grabadora digital profesional para posteriormente ser transcritos y analizados.

\subsubsection{Descripción detallada del instrumento que se presenta en Cifuentes y Salamanca (2012)}

Como señalamos, el instrumento consiste en la asociación de estímulos mixtos (imagen y enunciado) y se vale de tres tareas de reconocimiento y recuerdo de enunciados para la recogida de datos. Estas tareas son propuestas en orden creciente de dificultad y planteadas como un juego, para permitir que la atención de los informantes se desvíe de los datos fónicos estudiados y conseguir así un habla más espontánea. Dos ventajas tiene este instrumento: a) se focaliza en la información que el investigador desea obtener, pues los enunciados han sido elaborados previamente con un propósito ad hoc, y b) atenúa considerablemente

1 Para una descripción detallada de las características del instrumento, consúltese la tesis de Magíster en Lingüística de Cifuentes (2011). 
la influencia que el factor "consciencia de la producción fónica" puede tener en la pronunciación del sujeto, pues las tareas se le presentan como un desafío a su memoria y no como una pesquisa a nivel fonético.

En nuestra investigación, se utilizaron las tareas 1 y 3 de este instrumento, las cuales se describen a continuación:

\section{a) Tarea 1}

Se le presentan al informante, a través de un powerpoint, series de tres imágenes, asociadas cada una con un estímulo auditivo que contiene la variable que se desea investigar. Dicho estímulo consiste, en nuestro caso, en enunciados grabados previamente por un hablante extranjero, que contienen la secuencia grafémica "hu+vocal" en distintos contextos y con sintagmas en un orden no canónico. Posteriormente, al informante se le presentan sólo las imágenes; luego de lo cual, dado que ha memorizado y ordenado mentalmente los enunciados, debe pronunciarlos tres veces en un tiempo determinado.

Así, por ejemplo, en nuestra investigación, los sujetos veían, entre otras, la siguiente serie de imágenes:
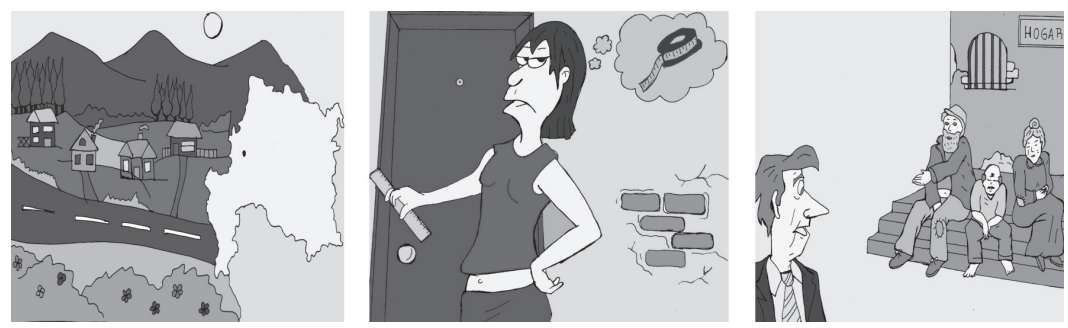

Esto, mientras escuchaban en un orden no canónico los enunciados "Hualqui es una linda ciudad", "Me hace falta una huincha" y "hay muchos ancianos abandonados", los cuales fueron grabados previamente por un hablante de chino mandarín con un precario dominio del español. Después de esto, a los sujetos se les presentaban sólo las imágenes, y se les solicitaba que recordaran los enunciados escuchados y los dijeran en un orden "normal" del español, dentro de un lapso de 7 segundos.

\section{b) Tarea 2}

Una serie de enunciados grabados por los mismos locutores chinos se les presentaba a los informantes en forma ralentizada y asociada 
con imágenes ad hoc. La tarea del informante consistía en descifrar el enunciado dicho por el locutor extranjero y, apoyado por la imagen, sin el estímulo fónico, recordarlo y pronunciarlo a velocidad normal.

\subsection{Transcripción del material}

Para la transcripción fonética del material recolectado, utilizamos el alfabeto de la IPA, en las fuentes que provee SIL (concretamente, SILSophiaIPA93).

Cabe hacer presente que en esta investigación sólo se consideró el análisis auditivo del material recolectado. En este sentido, un apoyo importante para la mejor discriminación de los sonidos fue el programa Audacity.

\subsection{Contextos y enunciados para la elicitación}

Las dos tablas siguientes contienen los enunciados que se utilizaron para elicitar los datos con el instrumento que presentaron Cifuentes y Salamanca (2012) y la lectura en voz alta, respectivamente. Se explicita en ellas el estatus de dichos enunciados (Reactivo de la Investigación (R.I.) o Distractor (D.)) y el contexto donde aparece la secuencia "hu+vocal" (inicial de enunciado (\#__), entre vocales $\left(\mathrm{V}_{-} \_\mathrm{V}\right)$, después de consonante nasal $(/ \mathrm{n} / \ldots)$, después de consonante lateral $(/ 1 / \ldots)$, después de consonante vibrante $\left(/ \mathrm{r} / \_\right.$) y después de consonante fricativa dorsoalveolar (/s/__). 
Tabla 1. Enunciados elicitados de acuerdo con el instrumento de Cifuentes y Salamanca (2012)

\begin{tabular}{|c|c|c|}
\hline Enunciado & Estatus & Contexto \\
\hline 1.- Hualqui es una linda cuidad. & R.I. & $\#$ \\
\hline 2.- Huele muy mal aquí. & R.I. & \#_- \\
\hline 3.- Asaltaron a mi amigo. & D. & ---- \\
\hline 4.- Huevón no siempre es un insulto. & R.I. & \#_- \\
\hline 5.- Comenzó la huelga. & R.I. & $\mathrm{V}_{-} \mathrm{V}$ \\
\hline 6.- Me encantan las ensaladas. & $\mathrm{D}$ & ---- \\
\hline 7.- El viejito repara huesos. & R.I. & $V_{-} \mathbf{V}$ \\
\hline 8.- Me hace falta una huincha. & R.I. & $\mathbf{V}_{-} \mathbf{V}$ \\
\hline 9.- No tengo señal. & D. & ---- \\
\hline 10.- Es rico el pan con huevo. & R.I. & $\mathbf{n}_{-}$ \\
\hline 11.- El campesino tiene un huerto grande. & R.I. & n_ \\
\hline 12.- Hay muchos ancianos abandonados. & D. & --- \\
\hline 13.- Me gusta el mote con huesillo. & R.I. & $\mathbf{n}_{-}$ \\
\hline 14.- No se debe cazar huemules. & R.I. & $r_{-}$ \\
\hline 15.- A ella le encanta mirarse al espejo. & D. & ----- \\
\hline 16.- Va a usar huascas para castigarla. & R.I. & $r_{-}$ \\
\hline 17.- Quieren comprar Huachipato. & R.I. & $r$ \\
\hline 18.- El árbitro mostró tarjeta roja. & D. & $\begin{array}{ll}--- \\
---\end{array}$ \\
\hline 19.- El huaso usa manta y sombrero. & R.I. & 1 \\
\hline 20.- Deben tapar el hueco. & R.I. & 1 \\
\hline 21.- Se desmayó por la inyección. & D. & ---- \\
\hline 22.- El huésped se fue. & R.I. & 1 \\
\hline 23.- Nos trataron como simples huachos. & R.I. & s_ \\
\hline 24.- Los estudiantes usamos computadores. & D. & ------ \\
\hline 25.- Tengo que limpiar las huellas de perro. & R.I. & $s_{-}$ \\
\hline 26.- Hay muchos niños huérfanos. & R.I. & s_- \\
\hline 27.- Le regalaron un perrito. & D. & ---- \\
\hline
\end{tabular}


Tabla2. Enunciados elicitados a través de la lectura en voz alta

\begin{tabular}{|c|c|c|}
\hline Enunciado & Estatus & Contexto \\
\hline 1. Reventó los globos & D. & ----- \\
\hline 2. Huevón y fresco es el tipo & R.I. & \#_ \\
\hline 3. Nos preparamos para la huelga. & R.I. & $V_{-} \mathbf{V}$ \\
\hline 4. Hualqui está en la Octava Región & R.I. & \#_ \\
\hline 5. Arriba en la cordillera & D & ----- \\
\hline 6. Mi amigo colecciona huesos. & R.I. & $\mathrm{V}_{-} \mathrm{V}$ \\
\hline 7. Me compré una huincha. & R.I. & $\mathrm{V}_{-} \mathrm{V}_{\mathrm{C}}$ \\
\hline 8. Huele a peligro & R.I. & \#_- \\
\hline 9. Yo no recuerdo esa canción & D. & ---- \\
\hline 10. Me gusta el arroz con huevo. & R.I. & $\mathbf{n}_{-}$ \\
\hline 11. Lloré alrededor de su cama & D. & ---- \\
\hline 12. Visitamos un huerto precioso & R.I. & $\mathbf{n}_{-}$ \\
\hline 13. Me entretenía asustar huemules. & R.I. & $r$ \\
\hline 14. Se enredó por completo & D. & ---- \\
\hline 15. En la feria se pueden comprar huascas. & R.I. & $r_{-}$ \\
\hline 16. Hay que internacionalizar Huachipato. & R.I. & $\mathbf{r}_{\text {_ }}$ \\
\hline 17. El que ríe último ríe mejor. & D. & ----- \\
\hline 18. El huaso no baila cumbia. & R.I. & 1 \\
\hline 19. Se escondió en el hueco que quedó en la pieza. & R.I. & 1 \\
\hline 20. Odio las rutinas. & D. & ----- \\
\hline 21. Es el huésped ideal. & R.I. & 1 \\
\hline 22. Son unos pobres huachos. & R.I. & s_- \\
\hline 23. No me hablen de inyecciones & D. & ---- \\
\hline 24. Dejaron las huellas de su delito. & R.I. & s_- \\
\hline 25. Me da tristeza ver tantos niños huérfanos. & R.I. & $s_{-}$ \\
\hline 26. Prefiero el mote sin huesillos. & R.I. & n_ \\
\hline 27.- Le regalaron un perrito. & D. & ----- \\
\hline
\end{tabular}




\section{Análisis y resultados}

\subsection{Segmentos fónicos encontrados}

De acuerdo con nuestros datos, los fonos que realizan la secuencia grafémica "hu+vocal" son cuatro:

\begin{tabular}{|c|l|}
\hline Fono & \multicolumn{1}{|c|}{ Descripción articulatoria } \\
\hline$[\mathrm{g}]$ & Oclusivo, velar, sonoro, oral. \\
\hline$[\mathrm{\gamma}]$ & Fricativo, velar, sonoro, oral \\
\hline$\left[\mathrm{\gamma}_{\tau}\right]$ & Aproximante, velar, sonoro, oral. \\
\hline$[\mathrm{w}]$ & Semiconsonante, muy alta, posterior, redondeada. \\
\hline
\end{tabular}

\subsubsection{Comentarios}

Luego de escuchar -los dos investigadores- todos y cada uno de los enunciados, a lo menos tres veces, se procedió a transcribirlos y cotejar dichas transcripciones. Hubo consenso en la mayoría de ellas. Las pocas transcripciones que no fueron consensuadas se volvieron a escuchar y discutir, después de lo cual se obtuvo un acuerdo final y, con ello, un consenso en la transcripción de todo el material fónico registrado.

Asílas cosas, se pudo establecer que son cuatrolos fonos discriminables de manera consistente, que instancian la secuencia "hu+vocal"; tres de ellos, claramente consonánticos (uno oclusivo, uno fricativo y uno aproximante) y uno con un estatus semiconsonántico. Para enfatizar la diferencia articulatoria y perceptual de este último fono con respecto a los demás, lo hemos descrito con parámetros propios de los sonidos vocálicos (muy alto, posterior, redondeado). Distinguir más -o menosde estos cuatro sonidos nos parece una sobre -o sub- diferenciación que no se condice con la evidencia empírica recogida. 


\subsection{Resultados generales}

\begin{tabular}{|c|c|c|c|c|c|c|}
\hline \multicolumn{3}{|c|}{} & \multicolumn{4}{c|}{$\mathrm{C}$} \\
\hline & $\# \_$ & $\mathrm{V}_{-} \mathrm{V}$ & $/ \mathrm{n} / \ldots$ & $/ 1 / \ldots$ & $/ \mathbf{r} / \ldots$ & $/ \mathrm{s} / \ldots$ \\
\hline$[\mathrm{g}]$ & $30,80 \%$ & 0 & $61,76 \%$ & $4,83 \%$ & $0,51 \%$ & $0,51 \%$ \\
\hline$[\mathrm{\gamma}]$ & $10,10 \%$ & $15,95 \%$ & 0 & $22,70 \%$ & $32,65 \%$ & $4,61 \%$ \\
\hline$\left[\gamma_{\tau}\right]$ & $49 \%$ & $61,79 \%$ & $37,74 \%$ & $62,80 \%$ & $59,70 \%$ & $61,02 \%$ \\
\hline$[\mathrm{w}]$ & $10,10 \%$ & $22,34 \%$ & $0,49 \%$ & $9,66 \%$ & $7,14 \%$ & $33,86 \%$ \\
\hline TOTAL & $100 \%$ & $100 \%$ & $100 \%$ & $100 \%$ & $100 \%$ & $100 \%$ \\
\hline
\end{tabular}

\subsubsection{Comentarios}

Es interesante observar que el fono aproximante es el que posee mayor frecuencia en 5 de los 6 contextos considerados. Además, en todos ellos, la diferencia es apreciable con respecto al fono cuya frecuencia está más próxima (entre 18 y 40 puntos porcentuales de diferencia). Particularmente relevante resulta advertir que uno de estos contextos es la posición inicial absoluta, pues, por lo menos en aquellas palabras cuyo fonema inicial es $/ \mathrm{g} /$, se ha propuesto tradicionalmente que predomina la realización oclusiva $[\mathrm{g}]$. En el único contexto en que el fono aproximante no es mayoritario, es después de consonante nasal. El fono mayoritario aquí es, precisamente, el oclusivo [g], lo cual coincide con lo expectable; sin embargo, se releva el hecho de que en esa posición ocurre un no despreciable $33,16 \%$ de realizaciones aproximantes.

Aunque no constituye el segmento más frecuente en ningún contexto, [w] tiene su porcentaje de aparición más alto después de / s/, lo cual se puede explicar por la frecuente realización [h] de este fonema, en este contexto.

\subsection{Consideraciones sobre la interpretación fonológica de los fonos encontrados}

Si la determinación de la forma básica del fonema se hiciese sólo a partir de la frecuencia de las realizaciones que lo instancian, claramente el fono seleccionado sería el aproximante, pues la sumatoria total de fonos muestra lo siguiente: 


\begin{tabular}{|c|c|c|}
\hline Realizaciones & $\mathbf{n}$ & Porcentajes \\
\hline$[\mathrm{g}]$ & 206 & $17,31 \%$ \\
\hline$[\mathrm{\gamma}]$ & 176 & $14,78 \%$ \\
\hline$\left[\mathrm{\gamma}_{\tau}\right]$ & 658 & $55,29 \%$ \\
\hline$[\mathrm{w}]$ & 150 & $12,6 \%$ \\
\hline Total & 1190 & $100 \%$ \\
\hline
\end{tabular}

Sin embargo, dado que la organización fonológica es, por definición, una organización del sistema fónico de una lengua, para hacer afirmaciones más concluyentes se requerirá revisar toda la clase natural de las oclusivas sonoras, así como de las realizaciones del fonema / dz/ y de la secuencia grafémica "hi+vocal", pues, de acuerdo con la línea teórica que hemos adoptado aquí, los sistemas fónicos de las lenguas tienden a la simetría (Burquest, 2009; Salamanca, Cifuentes y Figueroa, 2011) y, en consecuencia, el comportamiento de una parte del sistema puede orientar las decisiones con respecto a otra parte del mismo.

\subsection{Producciones de acuerdo con la variable género}

\subsubsection{Hombres}

\begin{tabular}{|c|c|c|c|c|c|c|}
\hline \multicolumn{2}{|c|}{} & \multicolumn{4}{c|}{$\mathrm{C}$} \\
\hline & $\#_{-}$ & $\mathrm{V}_{-} \mathrm{V}$ & $/ \mathrm{n} / \ldots$ & $/ 1 / \ldots$ & $/ \mathbf{r} / \ldots$ & $/ \mathrm{s} / \ldots$ \\
\hline$[\mathrm{g}]$ & $34,40 \%$ & 0 & $69,76 \%$ & $2,8 \%$ & $1,08 \%$ & 0 \\
\hline$[\mathrm{\gamma}]$ & $9,67 \%$ & $22,72 \%$ & 0 & $38 \%$ & $36,95 \%$ & $5 \%$ \\
\hline$\left[\mathrm{\gamma}_{\tau}\right]$ & $53,78 \%$ & $61,38 \%$ & $30,24 \%$ & $58 \%$ & $58,70 \%$ & $70 \%$ \\
\hline$[\mathrm{w}]$ & $2,15 \%$ & $15,90 \%$ & 0 & $1,2 \%$ & $3,27 \%$ & $25 \%$ \\
\hline TOTAL & $100 \%$ & $100 \%$ & $100 \%$ & $100 \%$ & $100 \%$ & $100 \%$ \\
\hline
\end{tabular}

5.4.2. Mujeres

\begin{tabular}{|c|c|c|c|c|c|c|}
\hline & & & \multicolumn{4}{|c|}{ C. } \\
\hline & \#__ & V__V & $/ \mathrm{n} /$ & $/ 1 /$ & $|\mathbf{r}|$ & $|s|$ \\
\hline [g] & $27,35 \%$ & 0 & $58,92 \%$ & $6,48 \%$ & 0 & $1 \%$ \\
\hline [४] & $9,43 \%$ & $11,65 \%$ & 0 & $17,60 \%$ & $26,78 \%$ & $3,85 \%$ \\
\hline$\left[\gamma_{T}\right]$ & $46,22 \%$ & $66,02 \%$ & $40,18 \%$ & $68,52 \%$ & $64,30 \%$ & $54,80 \%$ \\
\hline [w] & $16,98 \%$ & $22,33 \%$ & $0,90 \%$ & $7,40 \%$ & $8,92 \%$ & $40,40 \%$ \\
\hline TOTAL & $100 \%$ & $100 \%$ & $100 \%$ & $100 \%$ & $100 \%$ & $100 \%$ \\
\hline
\end{tabular}




\subsubsection{Comentarios}

Si bien los datos, en general, no muestran grandes diferencias, es interesante observar que la frecuencia de aparición de la semiconsonante es siempre mayor en los sujetos de sexo femenino. En un caso, esta diferencia es mínima (después de /n/), pero en los 5 casos restantes esta diferencia es superior a 5 puntos porcentuales; incluso, en posición inicial y después de / $\mathrm{s}$ / esta diferencia es superior a los 12 puntos porcentuales.

Por otro lado, es interesante observar que la consonante oclusiva -también la fricativa- tiende a predominar entre los sujetos de sexo masculino; al menos esto es claro en aquellos casos donde las diferencias entre ambos porcentajes son más pronunciadas. En efecto, si consideramos la posición inicial, se observa que existe una diferencia de 7 puntos porcentuales "a favor" de los hombres. Algo semejante ocurre después de consonante nasal, donde un 69,76\% de los hombres utiliza el fono oclusivo, contra un $58,92 \%$ del sexo femenino.

Así las cosas, nuestros datos no descartarían, inicialmente, una interpretación que sugiriera que, cuando existen distintas variantes posibles, los hombres tienden a seleccionar sonidos más "duros" / "explosivos" (oclusivos), incluso "estridentes" (fricativos); y las mujeres sonidos más "suaves"/ "lenis" (semiconsonánticos). Esta última afirmación con respecto a las realizaciones de los sujetos de sexo femenino, sin embargo, debe enfatizarse que aplica estrictamente a la realización semiconsonántica, pues, como se observa en la tabla, el sonido aproximante no tiene un comportamiento homogéneo. En efecto, se presenta con una frecuencia mayor en los hombres en contexto \#_ $y$, sobre todo, / s / _ p pero es mayor en las mujeres en contexto $V_{\_} V_{,} / \mathbf{r} / \_$, sobre todo, /n/ _ y / / _. Así las cosas, una afirmación más concluyente, que confirme o cuestione la tendencia que presentan estos datos, provendrá del análisis de cantidades más abultadas de datos.

\subsection{Comparación de nuestros datos con los obtenidos por Calvo (2008)}

Hasta donde sabemos, no existen en nuestro país estudios focalizados en la interpretación fonético-fonológica del continuo que va desde / $\mathrm{u}$ / a /g/ (tampoco desde / i / a / dz/), en general, ni en la realización de la secuencia grafémica "hu+vocal" (tampoco "hi+vocal"), en particular. En este sentido, como hemos dicho en las páginas iniciales de este trabajo, 
nuestro estudio constituye un aporte pionero. Ahora, el estudio al que hemos podido acceder que más se acerca al que aquí realizamos y que, en consecuencia, hace más comparable nuestros datos, es el de Calvo $(2008)^{2}$. Esta autora presenta los siguientes resultados:

\begin{tabular}{|l|l|l|}
\hline $\begin{array}{l}\text { Palabra en posición } \\
\text { inicial }\end{array}$ & $\begin{array}{l}\text { Con } \\
\text { consonantización }\end{array}$ & $\begin{array}{l}\text { Sin } \\
\text { consonantización }\end{array}$ \\
\hline Huevo & ['gweßo]: 14.28 & ['weßo]: 71.42\% \\
\hline & ['yweßo]: 14.28 & \\
\hline & & 28.56 \\
\hline Huecos & ['gwekos]: 28.57 & ['wekos]: 42.85 \\
\hline & ['ywekos]: 28.57 & \\
\hline & 57.14 & \\
\hline Huesos & ['gwesos]: 14.28 & [wesos]: 85.72 \\
\hline \multicolumn{1}{|c|}{33.3} & 66.66 \\
\hline
\end{tabular}

Si ordenamos nuestros datos para hacerlos comparables con la tabla de Calvo, obtenemos lo siguiente:

\begin{tabular}{|c|c|c|}
\hline & $\begin{array}{c}\text { Oclusiva y frivativa velares } \\
\left(\# \_\right)\end{array}$ & $\begin{array}{c}\text { Aproximante velar labializada } \\
\text { y semiconsonante (\#_) }\end{array}$ \\
\hline$\%$ & 40.9 & 59.1 \\
\hline
\end{tabular}

\subsubsection{Comentarios}

En primer lugar, estimamos que nuestra distinción de cuatro fonos es más realista que la distinción de tres, propuesta por Calvo (donde, si entendemos bien, la consonante aproximante y la semiconsonante se reúnen en una sola representación [W]).

Por otra parte, se puede observar que, en la posición inicial, los sujetos que participaron en nuestra investigación realizaron una mayor cantidad de fonos oclusivos y fricativos ([g] y [Y]) que los sujetos que participaron en la investigación de Calvo. Por esta misma razón, no resulta obvio para nosotros que la forma básica del fonema se deba

2 Aunque sólo se focaliza en las realizaciones de la secuencia "hu+vocal" en posición inicial. 
buscar entre las realizaciones aproximante y semiconsonántica, aunque sí constituye una hipótesis que debe explorarse prioritariamente a la luz del comportamiento de los otros segmentos con los cuales se organizan como clases naturales.

En este mismo contexto, resulta interesante observar los resultados que arrojó la indagación de Calvo para la secuencia "hi+vocal" (también en posición inicial de enunciado):

\begin{tabular}{|l|l|l|}
\hline $\begin{array}{l}\text { Palabra en posición } \\
\text { inicial }\end{array}$ & $\begin{array}{l}\text { Con } \\
\text { consonantización }\end{array}$ & $\begin{array}{l}\text { Sin } \\
\text { consonantización }\end{array}$ \\
\hline Hierro & $0 \%$ & ['jero]: $100 \%$ \\
\hline & & \\
\hline Hielo & $0 \%$ & ['jelo]: $100 \%$ \\
\hline & & \\
\hline Hierba & $0 \%$ & ['jerba]: $100 \%$ \\
\hline
\end{tabular}

Como se ve, en los informantes de Costa Rica no se produce consonantización alguna en las realizaciones de la secuencia "hi+vocal". Por lo mismo, teniendo a la vista las realizaciones de "hu+vocal" y "hi +vocal", la investigadora concluye que:

Este grupo de palabras presenta resultados interesantes en el sentido de que los diptongos iniciales con ie se dan en un $100 \%$ sin ningún tipo de consonantización al inicio de la palabra. Esto apoya la propuesta de la investigadora en el sentido de que, efectivamente, se dan diptongos en posición inicial, con sus variantes semiconsonánticas adscritas al fonema vocálico /i / . Al preguntarle a una persona cualquiera que si le parecía que yerba 'hierba' o yelo 'hielo' sonaban bien, contestó que esa era una pronunciación incorrecta.

Por otro lado, los diptongos iniciales con ue fueron un poco más susceptibles de consonantización, aunque no en la cantidad en que los autores anteriores señalan para esta posición (...)

La investigadora, a la luz de los datos, supone que la interpretación fonológica más adecuada sigue siendo la tradicional, propuesta por Navarro Tomás, la cual propone 
que existen diptongos en posición inicial absoluta y que estos se representan por los fonemas /i/ / $/$ y la vocal -alta del núcleo. En la pronunciación de los diptongos iniciales ie, se ha observado, en un $100 \%$ de los casos, la realización fonética de [j] aproximante o semiconsonántica, sin ningún tipo de obstrucción o consonantización. (Calvo, 2008: 135).

Aunque aún no hemos realizado una investigación cuyo foco sea la secuencia "hi+vocal", datos preliminares aportados por el piloteo del instrumento propuesto en Cifuentes (2011) muestran realizaciones con consonantización en ese contexto, lo que hace improbable la coincidencia con la interpretación de Calvo.

\section{Consideraciones finales}

En primer lugar, hay que relevar un problema que podría parecer menor, pero que a la luz de nuestra y otras investigaciones no lo es: qué estamos representando cuando recurrimos a determinados símbolos. Por ejemplo, ¿hay alguna diferencia entre $[\mathrm{w}] \mathrm{y}\left[\mathrm{\gamma}_{\mathrm{r}}{ }^{\mathrm{w}}\right]$ ? La respuesta será distinta si nos basamos en el inventario de símbolos propuesto por AFI, o en la tradición fonética hispánica. Esto nos lleva al problema teórico de determinar hasta dónde extender las diferencias de modo que ameriten una representación. Y este, como decíamos, no es un problema menor, porque tiene implicaciones al momento de establecer comparaciones, pues lo que se quiere en las disciplinas en general, y en la fonética en particular, es comparar peras con peras y manzanas con manzanas. En este sentido, sería deseable que las descripciones fonético-fonológicas no sólo entreguen las características articulatorias de los fonos que se presentan, sino los datos fónicos mismos (vía adjuntar en sus versiones electrónicas los archivos de audio correspondientes, por ejemplo). Esto con la finalidad de que las comparaciones no adolezcan de una falla estructural de inicio: que no haya claridad con respecto a cuál es el correlato fónico preciso de un determinado símbolo fonético o de una descripción articulatoria. Lo dicho es particularmente cierto, como se vio en la sección introductoria, cuando se trata de los sonidos glides, pues, por ejemplo, hasta hoy no hay consenso con respecto a si hay o no diferencias entre una glide prenuclear $\mathrm{y}$ postnuclear que justifiquen distintas representaciones. Y como esto se relaciona directamente con nuestro trabajo, por lo menos en lo que a $[w]$ se refiere, constituye un punto importante a considerar. Por otro lado, a la discusión con respecto a si hay una diferencia entre la glide en 
posición prenuclear y postnucelar, se añade una pregunta con respecto a si hay alguna diferencia entre la glide en posición inicial absoluta y después de una consonante (¿es la misma articulación y, por lo tanto, amerita la misma transcripción el sonido inicial de una palabra del inglés como "wait", y el segundo sonido en una palabra del castellano como "pueblo"?).

Hechos estos alcances, podemos señalar que en esta investigación se determinó empíricamente que la secuencia "hu+vocal” se realiza a través de 4 segmentos: un fono oclusivo, velar, sonoro, oral [g]; uno fricativo, velar, sonoro, oral [ $\left.\chi_{]}\right]$; uno aproximante, velar, sonoro, oral $[\mathrm{\gamma}]$; y uno semiconsonántico, muy alto, posterior, redondeado [W]. Nos parece que lo anterior constituye un avance importante con respecto a la mayoría de los trabajos precedentes que versan sobre el tema, pues, como hemos dicho en las páginas introductorias, uno de los problemas que presentan dichos trabajos es que, en su gran mayoría, organizan fonológicamente un material fonético que no tiene un sustento empírico explícito, o que coincide con el idiolecto del investigador. Por otro lado, no sólo hemos determinado qué fonos realizan efectivamente esta secuencia, sino que, además, hemos precisado la frecuencia con que lo hacen. En efecto, hemos determinado que la consonante oclusiva [g] ocurre en el 17.35\% de los casos; la fricativa [ $\mathbf{\gamma}$ ], en el 14,78\%; la aproximante [ $\mathbf{\gamma}$ ],? ?en el 55.29 $\%$; y la semiconsonante [W], en el 12,6\%. Con ello, hemos cumplido con el primer objetivo que nos propusimos con esta investigación, esto es, determinar qué segmento(s) realiza(n) la secuencia grafémica "hu+vocal" en un grupo de sujetos jóvenes de la comuna de Concepción.

Basados en estos resultados, hemos discutido sobre la organización fonológica más adecuada de estos segmentos. En este sentido, hemos dicho que si la frecuencia fuera el factor determinante para la selección de la forma básica, tendríamos que seleccionar la realización aproximante, acercándonos, así, a la interpretación de Cepeda (1991)³. Sin embargo, siguiendo a Salamanca, Cifuentes y Figueroa (2011), estimamos que la frecuencia constituye sólo uno de los criterios que se debe considerar al momento de determinar la forma básica del fonema; incluso, en forma prioritaria se debe considerar la plausibilidad de la direccionalidad del

3 Decimos "acercándonos" -y no "coincidiendo"- porque, como hemos dicho, Cepeda no aborda la secuencia "hu+vocal", sino las realizaciones del fonema cuya forma básica se ha transcrito tradicionalmente como $/ \mathrm{g} /$. 
cambio, la simetría del sistema y la fonotaxis de los fonos en cuestión. Esto es más pertinente aún, si se considera que, a diferencia de los datos aportados por Calvo (2008) para el español de Costa Rica, en nuestros datos ocurre un no despreciable $30,8 \%$ de realizaciones oclusivas en una posición prominente como la inicial. En este contexto, y tal como hemos dicho en algunos comentarios precedentes, resultará fundamental observar el comportamiento de la clase natural de las oclusivas sonoras, en todos los contextos posibles, así como de las realizaciones de "hi+vocal" y la secuencia que va de /i/ a /dz/, para adoptar una decisión más concluyente.

Ahora, al señalar que, por lo menos atendiendo a su frecuencia, debe plantearse la hipótesis de que la realización aproximante se constituya en la forma básica del fonema, respondemos a otro de los objetivos que nos propusimos con esta investigación.

En relación con la comparación entre las producciones por la variable sexo, se puede apreciar que, si bien los datos muestran una tendencia a la homogeneidad, la frecuencia de aparición de la semiconsonante [w] es siempre mayor en los sujetos de sexo femenino, y que la consonante oclusiva $[\mathrm{g}]$ y fricativa $[\mathbf{\gamma}]$ tienden a predominar entre los sujetos de sexo masculino.

Por último, nos parece que la toma de muestras a través del instrumento que se presenta en Cifuentes y Salamanca (2012) y la lectura en voz alta -en ese orden- es una combinación que tributa a la mejor obtención de los datos. Recordemos que si la recogida de éstos se realizara, como no es poco común, sólo a través de la lectura en voz alta, habría dudas razonables con respecto a si la artificialidad de la situación podría haber condicionado la ocurrencia de determinadas producciones; aunque, sin duda, sería ventajoso, pues se perdería el mínimo de información, dado que es el investigador quien elabora previamente los reactivos. Por otro lado, como bien se destaca en Cifuentes y Salamanca (2012), la captura de datos (semi)espontáneos a través de los procedimientos tradicionales (observaciones, entrevistas, etc.), aunque ventajosa por la obtención de información más cercana al "habla real", se torna habitualmente compleja, pues, dado que el investigador no tiene mayor incidencia en los datos que se elicitan, la cantidad de ellos que finalmente se obtienen para cada contexto puede ser muy disímil, lo que supone conclusiones con distintos grados de consistencia. 
Un ejemplo de lo que acabamos de señalar se presenta en Cepeda (1991: 53), donde la cantidad total de realizaciones de /g/ que se presenta por cada contexto son muy diferentes. En efecto, mientras en posición de inicio de sílaba, después de vocal, es de 689, en posición inicial absoluta -un contexto particularmente relevante- es de, apenas, 16. En nuestro trabajo, en cambio, al combinar la lectura en voz alta con el instrumento basado en imágenes, hemos obtenido 202 realizaciones en contexto intervocálico y 191 en posición inicial absoluta, lo que, sin duda, da mayor consistencia a los resultados.

En relación con las proyecciones de este estudio, tres han sido sugeridas en este trabajo: a) realizar estudios que determinen los segmentos que instancian la secuencia grafémica "hi+vocal", las realizaciones para toda la serie de oclusivas sonoras -en la mayor cantidad de contextos posibles-, y las realizaciones de la africada /dz/; todo lo cual, junto con su valor intrínseco, permitirá orientar la decisión "final" con respecto a la forma básica del fonema que agrupa las realizaciones de "hu+vocal"; b) también es deseable la ampliación de la muestra; en el mejor de los casos, estratificada de acuerdo con el nivel sociocultural de los sujetos y c) es deseable la aplicación de estadígrafos que den cuenta de diferencias estadísticamente significativas entre los datos.

Por distintos motivos, estos aspectos no formaron parte de nuestra investigación. Sin embargo, creemos que el hecho de haber puesto en el tapete el tema de la realización fonética y la organización fonológica de los segmentos deslizados en el español de Chile; así como haber determinado qué fonos realizan efectivamente la secuencia "hu+vocal" -y en qué proporción- constituye un aporte relevante de nuestro trabajo, que señala un buen punto de partida en esta amplia temática.

\section{Referencias}

Aguilar, L. (1994). Los procesos fonológicos y su manifestación fonética en diferentes situaciones comunicativas: La alternancia vocal/semiconsonante/consonante. Barcelona: Departamento de Filología Española, Universidad Autónoma de Barcelona. 
Alarcos, E. (1961). Fonología Española. Madrid: Gredos.

Bowen, J. y Stockwell, R. (1955). "The Phonemic Interpretation of Semivowels in Spanish". Language 31: 236-240.

Burquest, D. (2009). Análisis fonológico: Un enfoque funcional. Recuperado el 20 de julio de 2012, de http:// www.01.sil.org/ silepubs / Pubs/52264/Burquest_ AnalisisFonologico_52264.pdf

Calvo, A. (2008). "Las Semiconsonantes y Semivocales en los diptongos del español: propuesta de análisis fonológico". Filología y Lingüística XXXIV: 107-142.

Cepeda, G. (1991). Las consonantes de Valdivia. Valdivia: Universidad Austral de Chile.

Cifuentes, E. (2011). Desarrollo de un instrumento de recogida de datos para investigaciones en fonética y fonología. Tesis para optar al grado de Magister en Lingüística, Universidad de Concepción, Concepción, Chile.

. y Salamanca G. (2012). “Desarrollo y aplicación piloto de un instrumento para recoger datos del nivel fonéticofonológico". Literatura y Lingüística 25 (2): 221-248.

Cressey, W. (1978). Spanish phonology and morphology: a generative view. Washington: Georgetown University Press.

D’Introno, F. y otros. (1995). Fonética y Fonología actual del Español. Madrid: Cátedra.

Harris, J. (1983). Syllable Structure and Stress in Spanish: a Nonlinear Analysis. Cambridge, MA: The MIT Press.

Martínez Celdrán, E. (1993). Fonética. Barcelona: Teide. $4^{\text {a }}$ edición revisada.

. (1996). El sonido en la comunicación humana. Barcelona: Octaedro.

; E., Fernández Planas, A. M.; y Carrera, J. (2003). Illustrations of the IPA: Spanish. Journal of the International Phonetic Association 33 (2), 255-260. 
Mosterín, J. (1981). La ortografía fonémica del español. Madrid: Alianza Editorial, S.A.

Navarro, T. (1918). Manual de Pronunciación española. Madrid: Consejo Superior de Investigaciones científicas.

Núñez, R. \& Morales, A. (1999). Fonología generativa contemporánea de la lengua española. Washington DC: Georgetown University Press.

Obediente, E. (2007) [2005]. Fonética y Fonología. Venezuela: Universidad de Los Andes.

Quilis, A y J. Fernández. (1973). Curso de fonética y fonología españolas: para estudiantes angloamericanos. Madrid: Consejo Superior de Investigaciones Científicas.

- (1999). Curso de Fonética y Fonología Españolas. Madrid: Consejo Superior de Investigaciones Científicas.

Salamanca, G.; Cifuentes, E. y Figueroa, M. (2011). “Sistematización de criterios para la determinación de fonos, alófonos y formas básicas de los fonemas del español de Chile: una herramienta para la investigación y la docencia". Boletín de Filología 46: 107-133.

Saporta, S. (1956). “A Note on Spanish Semivowels". Language 32 (2): 287-290. 